soming of the biological sciences and their application in agriculture, the opening-up of arid areas by solar power, new methods of sterilizing and packaging, etc., offer prospects of a breathing space from the pressure of increase in population. Chemical control of mental disease might be a powerful weapon in the war against man's ills. Progress is also being made in the handling of giant molecules, which require a new type of chemical thinking. There have been great strides in the development of machines for supplementing and substituting human thought; but this process needs to go much further before we can cope with the complexities of the coming world. Dr. Bush referred specifically to problems of communication in which new techniques of electronic selection, photomicrography and facsimile transmission would replace the conventional library. There is, however, a reason for the search for knowledge which is inherent in the nature of man. His search for understanding is prompted not simply by his immediate needs for food and shelter, but also by his inherent urge to know. Science should be pursued, Dr. Bush concluded, in response to the urge which lies deep in all of us to press on towards greater understanding.

\section{The National Research Development Corporation}

IN the debates on the Development of Inventions Bill and again in the recent report on industry and science issued by the Manchester Joint Research Council, opinion was expressed that the work of the National Research Development Corporation is not sufficiently well known in industry. The NRDC Bulletin, of which the first number appeared in April (No. 1 ; pp. 20 ; 1954), is an attempt to remedy this position by informing industry of the inventions which can be made available by the Corporation in addition to, or in place of, the existing routine circulation procedure. It is hoped that in time the Bulletin, which will be published quarterly, will become the Corporation's chief vehicle for informing industry of such inventions. Each issue will include short notes of the inventions recently available, as well as on other inventions which have been the Corporation's property for some time and which it is considered should receive wider publicity. It is also proposed that each issue shall contain at least one article about other aspects of the Corporation's activities. Besides the descriptions of selected inventions, the present issue includes a note on the granting of licences and a list of the Corporation's patent. holdings, arranged in the eight groups : electronics; electrical engineering; mechanical engineering ; civil engineering; aero and auto engineering; scientific instruments ; chemistry and plastics ; miscellaneous and domestic. The Bulletin is obtainable from the Exploitation Officer, NRDC, 1 Tilney Stroet, London, W.1.

\section{Simultaneous Translation at a Scientific Meeting}

ON May 11, at a meeting held at the Institut Pasteur in Paris, Prof. J. H. Quastel, professor of biochemistry in McGill University, Montreal, delivered by invitation an address on "Soil Metabolism". The occasion was noteworthy for the use of a system of simultaneous translation, analogous to that used at meetings of the United Nations and similar bodies. Thus Prof. Quastel delivered his lecture in Fnglish, and the difficult task of simultaneous translation was carried out by Dr. P. R. Lépine, of the Institut Pasteur. Dr. Lépine had actually seen Prof. Quastel's manuscript for a short time before the meeting; it was nevertheless a considerable achievement to be able to give a simultaneous translation of a scientific discourse in a way which the audience found to be completely successful. At the conclusion of the lecture, Prof. J. Trefouël, director of the Institut Pasteur, thanked Prof. Quastel and, as is customary when distinguished visitors address the Institut Pasteur, presented to him a silver medal, which bears a figure of Pasteur by the sculptor Roty.

\section{Recognition of Intoxication}

Iv a study of the chemical diagnosis of alcoholic intoxication (S. Afr. J. Med. Sci., 18, 141; 1953), J. J. Prag has attempted to correlate the usual clinical criteria of drunkenness with blood-alcohol levels. The tests were made on a hundred motor-car' drivers, charged with driving under the influence of alcohol, and on a group of volunteers. One of his conclusions is that with blood-alcohol levels below 0.05 per cent (gm./per $100 \mathrm{ml}$.) nobody is intoxicated in the medico-legal sense, while with a level above 0.15 per cent most people (more than 90 per cent) are definitely intoxicated. The weakness of the chemical diagnosis lies in the blood-alcohol range between 0.05 and 0.15 per cent, where individual variations in symptoms are very great. The average ratio of blood-level to urine-level of alcohol was found to be $1: 1 \cdot 31$, though the blood-level reflects more directly the alcohol concentration affecting the nervous system. With a given amount of alcohol, the greatest degree of intoxication is reached well before the blood-level reaches its maximum. If sugar is taken with alcohol, the symptoms are more severe but pass off more quickly, apparently owing to more rapid absorption and removal of alcohol. The results of this work are, on the whole, in harmony with the recent report entitled "The Recognition of Intoxication" by the Committee of the British Medical Association (1954) under the chairmanship of Prof. E. J. Wayne. Both Prag and the Committee stress that symptoms of impaired judgment may appear after drinking small amounts of alcohol and long before the stage of definite intoxication is reached. Diagnosis of drunkenness should not depend solely on results of laboratory tests, but on clinical findings, combined, if possible, with laboratory tests.

\section{Tobacco Curing Studies}

BIOchemicat and physical changes which take place in tobaceo leaves during flue-curing are described in some detail by H. O. Askew et al. (N.Z. $J$. Sci. and Tech., B, 35, 4, 344; 1954). Data for changes in weight and moisture content of tobacco leaves during flue-curing show that the rate of loss of water is governed by the temperature and humidity conditions in the kiln. In the early stages of curing, 93-95 per cent of the loss of weight of the leaf is due to loss of water. During the colouring and fixing stages, rapid hydrolysis of starch to sugars, mainly glucose and fructose, and hydrolysis of proteinnitrogen to simpler compounds, take place. For the first $50 \mathrm{hr}$. of curing, the average rates of hydrolysis were : starch 0.35 per cent in two experiments; and protein-nitrogen 0.5 per cent and 0.7 per cent, respectively. Increase in reducing-sugars content was proportional to the amounts of protein and of starch hydrolysed. Loss of dry-matter can be nearly completely accounted for by requirements of water, by the products of hydrolysis, and by difference between over-all loss of starch and that required for 